\title{
EDITORIAL
}

\section{TENDÊNCIAS DA PESQUISA SOBRE O CUIDADO DE ENFERMAGEMa}

\author{
A na Luísa Petersen COG O ${ }^{b}, M$ aria da G raça de Oliveira CROSSE T TI ${ }^{c}$
}

A pesquisa sobre o cuidado de enfermagem possui uma longa trajetória que acompanha a sua profissionalização desde F lorence N ightingale, considerando-se "N otas sobre a enfermagem"(1) um marco nas publicações sobre o tema com seus múltiplos desdobramentos. D esde então, os enfermeiros, comprometidos com a qual idade dos cuidados realizados junto ao paciente, seus familiares e a comunidade, têm intensificado a produção de pesquisas, de reflexões e de relatos de experiências das suas práticas cuidativas.

A Revista G aúcha de E nfermagem tem o privilégio de registrar um recorte da evolução das produções científicas desenvolvidas pela comunidade de enfermagem nacional, em diferentes contextos, desde 1976. É notório que a expansão dessa produção foi marcada sobremaneira pelo desenvolvimento dos cursos de pós-graduação e pelo fomento às pesquisas, mesmo que esses sejam, ainda hoje, quantitativamente insuficientes para 0 atendimento das demandas da área.

Nesse contexto, questiona-se quais tem sido as perspectivas e as tendências da pesquisa sobre 0 cuidado de enfermagem publicadas na R evista $G$ aúcha de E nfermagem. Primeiramente, buscou-se 0 entendimento do que seriam essas multiplicidades do cuidado em enfermagem, concordando-se que possui como atributos o cuidar de indivíduos e de grupos da concepção à mor te; educar e pesquisar no processo de cuidar, na educação permanente, na formação de novos profissionais e na produção do conhecimento; como também possui a dimensão administrativo-gerencial ${ }^{(2)}$.

A fim de conhecer as produções sobre o cuidado de enfermagem publicados na Revista $G$ aúcha de E nfermagem nos últimos cinco anos (2005 a 2009), procedeu-se à busca dos artigos que utilizaram os descritores cuidados de enfer magem e enfermagem.

I dentificou-se dezenove artigos, cujos autores eram procedentes das mais diversificadas Instituições de Ensino do Brasil. Predominaram os temas gerenciamento em enfermagem (oito artigos), humanização do cuidado (três artigos) e cuidado à criança hospitalizada (três artigos). Quanto ao tipo de artigo, foram 16 artigos originais, todos com abor dagem qual itativa, duas reflexões e um relato de experiência.

D eve-se considerar como limitações nos dados apresentados o fato de que a busca ocorreu a partir dos descritores indicados pel os autores e foram anal isados os resumos dos artigos. Assim, pode-se inferir que algum artigo sobre o tema cuidado em enfermagem possa ter sido excluído da busca por não estar especificado como descritor.

Concluíu-se que as produções sobre o cuidado de enfermagem na Revista $\mathrm{G}$ aúcha de $\mathrm{E}$ nfermagem são contínuas e apresentam a abordagem de temas que têm sido explorados ao longo dos últimos anos refletindo o momento social-político-econômico da enfermagem enquanto disciplina. Assim esse pressuposto se expressa no presente exemplar em que se constata a publicação de artigos com temas diversificados dados os diferentes contextos no qual o cuidado em enfermagem vem sendo estudados.

$\mathrm{N}$ esse contexto, tem-se como desafio a per spectiva de pensar criticamente o cuidado em enfermagem com olhares que sinalizem práticas (re)novadas que dêem retor no à sociedade.

\section{REFERÊNCIAS}

1 N ightingale F. N otas sobre a enfer magem: o que é e o que não é. São Paulo: ABE n; 1989.

2 Pires D. A enfermagem enquanto disciplina, profissão e trabalho. Rev Bras Enferm [ Internet] . 2009 [ citado 2010 mar 14] ;62(5):739-44. Disponível em: http:/ / www.scielo.br/ pdf/ reben/ v62n5/ 15.pdf.

\footnotetext{
a T exto elaborado a partir da pal estra de mesmo nome apresentada em 16 de abril de 2010 no Curso de G raduação em E nfermagem do I nstituto M etodista de Porto Alegre (IPA).

b Professora A djunta da E scola de Enfermagem da Universidade Federal do Rio Grande do Sul.

c Professora A ssociada da E scola de Enfermagem da U niversidade Federal do Rio Grande do Sul.
} 